This item was submitted to Loughborough's Research Repository by the author.

Items in Figshare are protected by copyright, with all rights reserved, unless otherwise indicated.

\title{
A pyrene-based approach to tune emission color from blue to yellow
}

\section{PLEASE CITE THE PUBLISHED VERSION}

http://dx.doi.org/10.1021/acs.joc.7b00685

\section{PUBLISHER}

(C) American Chemical Society (ACS)

\section{VERSION}

AM (Accepted Manuscript)

\section{PUBLISHER STATEMENT}

This work is made available according to the conditions of the Creative Commons Attribution-NonCommercialNoDerivatives 4.0 International (CC BY-NC-ND 4.0) licence. Full details of this licence are available at: https://creativecommons.org/licenses/by-nc-nd/4.0/

\section{LICENCE}

CC BY-NC-ND 4.0

\section{REPOSITORY RECORD}

Wang, Chuan-Zeng, Hisashi Ichiyanagi, Koya Sakaguchi, Xing Feng, Mark Elsegood, Carl Redshaw, and Takehiko Yamato. 2019. "A Pyrene-based Approach to Tune Emission Color from Blue to Yellow". figshare. https://hdl.handle.net/2134/25859. 


\section{A pyrene-based approach to tune emission color from blue to yellow}

Chuan-Zeng Wang, ${ }^{a}$ Hisashi Ichiyanagi, ${ }^{a}$ Koya Sakaguchi, ${ }^{a}$ Xing Feng, ${ }^{* b}$ Mark R.J. Elsegood, ${ }^{\mathrm{c}}$ Carl Redshaw, ${ }^{\mathrm{d}}$ and Takehiko Yamato*a

a Department of Applied Chemistry, Faculty of Science and Engineering, Saga University, Honjo-machi 1, Saga 840-8502 Japan, E-mail: yamatot@cc.saga-u.ac.jp.

b School of Printing and Packaging Engineering, Beijing Institute of Graphic Communication, 1 Xinghua Avenue (Band Two), Daxing, Beijing, 102600, P. R. China, E-mail: hyxhn@sina.com.

c Chemistry Department, Loughborough University, Loughborough, LE11 3TU, UK.

d School of Mathematics and Physical Sciences, The University of Hull, Cottingham Road, Hull, Yorkshire HU6 7RX, UK.

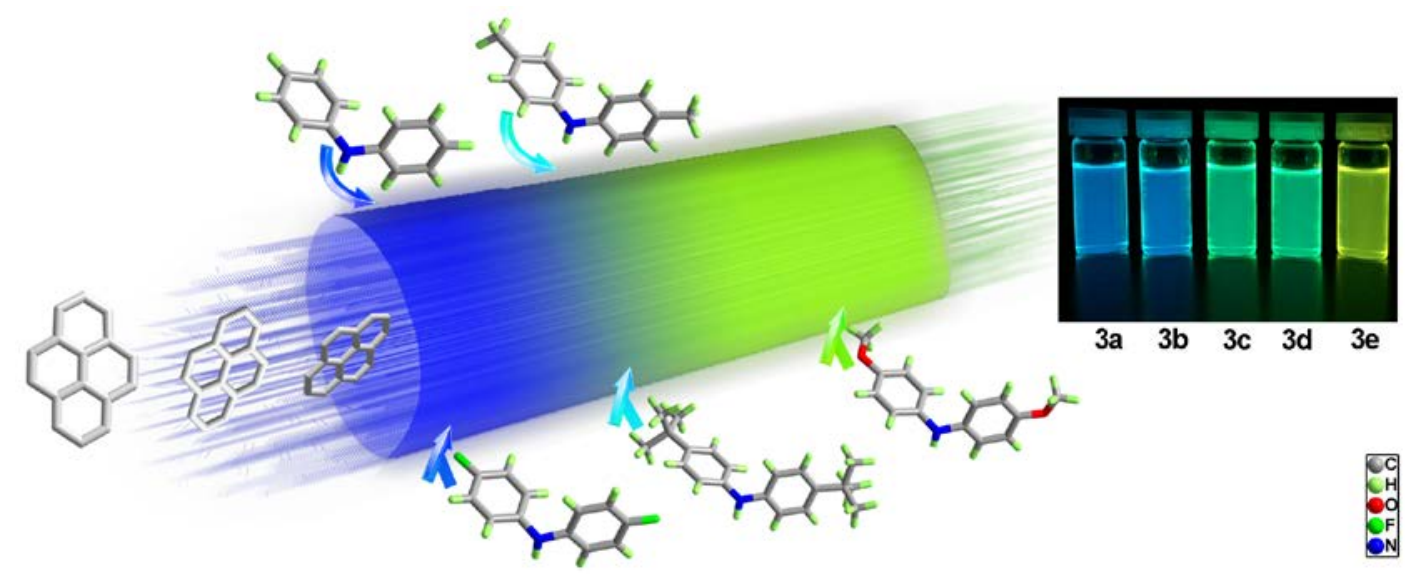

ABSTRACT: The development of functionalized, luminescent, pyrene-based monomers has been and continues to be an area of great interest in terms of the design and fabrication of optical and electronic devices. Herein, a facile strategy to tune the emission color of pyrene-based chromophores has been established by simple functional group modification at the para position to the diphenylamino on the donor building block. Intriguing photophysical properties were obtained and are described both in different solutions and in the solid state. The results obtained could be explained by the Hammett method and by density functional theory (DFT) calculations. A good correlation was observed between the Hammett $\sigma_{\text {para }}$ constants of the functional groups para to the phenyl and the wavenumber $\left(\mathrm{cm}^{-1}\right)$ of the emission profile. This positive correlation, namely between the $\sigma$ constants of the functional groups and the emission properties of the monomers, can be used to develop a predictive method for these types of systems. 


\section{INTRODUCTION}

Chromophores are a class of functional $\pi$-electron systems that have progressively established themselves as useful tuneable molecules in modern organic electronics and organic electronic devices. ${ }^{1}$ Indeed, it is important to have the ability to tune the emission property of materials in a facile approach when designing light-emitting diodes, ${ }^{2}$ bio-imaging probes, ${ }^{3}$ and other photoelectric emitting devices, ${ }^{4}$ particularly in the visible region. Various strategies have been established to achieve efficient full-color emitting materials which are based on underlying mechanisms, including intramolecular charge-transfer (ICT), ${ }^{5}$ twisted intramolecular charge-transfer (TICT), ${ }^{6}$ excimer, ${ }^{7}$ excited-state proton transfer (ESIPT), ${ }^{8}$ and photo-induced electron transfer (PET). ${ }^{9}$ Such strategies provide significant guidance when designing novel luminescent molecules. In particular, it is worth noting that in recent years the introduction of donors and acceptors has played a crucial role in organic electronics based on ICT. ${ }^{5,10}$ Furthermore, much effort has been devoted to developing highly efficient host materials.

Among the many promising unmodified host candidates, polyaromatic pyrene have attracted attention because of their high thermal and photochemical stability, pure blue fluorescence, planar geometry, and natural high charge carrier mobility. ${ }^{11}$ It is also possible to append electronaccepting/donor groups at the suitable positions on the pyrene core, which can result in enhanced intramolecular charge-transfer. Generally speaking, acceptors and donors provide energetically high lying occupied molecular orbitals (HOMOs) and low lying unoccupied molecular orbitals (LUMOs), respectively. The $\mathrm{D}-\mathrm{A}$ unit is conducive to the fine-tuning of the electronic interactions and charge transfer efficiencies. ${ }^{12}$ A wide variety of $\mathrm{D}-\mathrm{A}$ type pyrene derivatives have been investigated by comparing experimental and theoretical results in recent years. ${ }^{13}$ For instance, many pyrene-based chromophores, based on both covalent and acceptor-donor structures, have been found to possess differing yet distinctive emission properties by functionalization at the different positions of the pyrene core. ${ }^{4 a, 14}$ On the basis of these experimental observations, in case of a donor/acceptor substituted molecule, the band-gap of the new material can be significantly reduced when compared to the pure components. ${ }^{15}$

Herein, we present a facile strategy to investigate the influence of covalent donor groups. Specifically, a series of classical donor groups, which differ only by the functional group para to an $N, N$-diphenylamine core, have been studied. The groups were introduced at the 1-, and 3positions of 7-tert-butylpyrene via a Buchwald-Hartwig amination reaction. As anticipated, we observed distinct/different emission properties both in solution and in the solid state, simply by fine-tuning of the para substituents of the $N, N$-diphenylamine core. Broad and tuneable emis- 
sion, from blue to yellow wavelengths, were achieved in dilute $\mathrm{CH}_{2} \mathrm{Cl}_{2}$ solutions. Moreover, one of the compounds was found to emit orange light in the solid state. To decipher the underlying mechanisms responsible for these attractive properties, we further investigated the solvatochromism of the five compounds and report their absorption and emission spectra. The pronounced positive solvatochromism combined with theoretical calculations indicate that these systems have potential for the design of full-color organic electrochromic devices. ${ }^{1}$

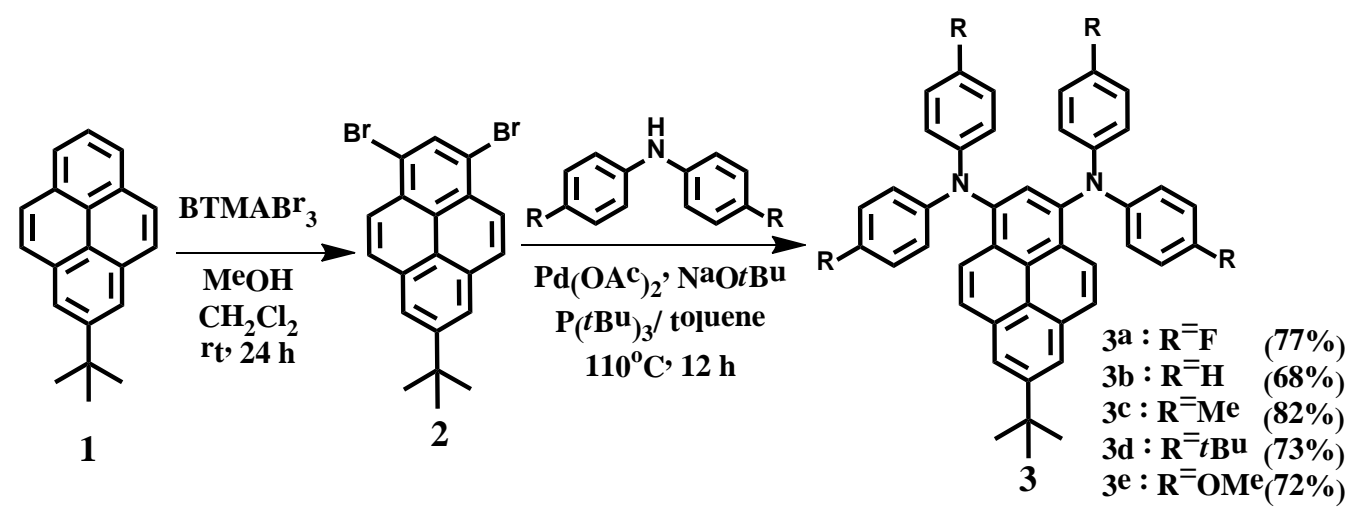

Scheme 1. Synthesis of pyrene-based light-emitting monomers 3.

\section{RESULTS AND DISCUSSION}

Shown in Scheme 1 is the synthesis of 3a-e starting from 7-tert-butylpyrene. This synthetic strategy was adapted from the well-known Buchwald-Hartwig amination reaction. The compounds were characterized by ${ }^{1} \mathrm{H}$ and ${ }^{13} \mathrm{C}$ NMR spectroscopy, high resolution mass spectrometry. The detailed synthetic procedures and characterization data are given in the Experimental Section and the Supporting Information (Figure S1-10). All compounds exhibited good solubility in common organic solvents with excellent thermal stability. The thermal properties of these monomers were determined by differential scanning calorimetry (DSC) and thermogravimetric analysis (TGA) under a nitrogen atmosphere and the results are shown in Table 1. Compounds of type 3 showed very high thermal stability with decomposition temperatures $\left(T_{\mathrm{d}}\right)$ of 348 to $392{ }^{\circ} \mathrm{C}$ and melting temperatures $\left(T_{\mathrm{m}}\right)$ of 198 to $262{ }^{\circ} \mathrm{C}$. The high thermal values endow high morphologic stability of the amorphous phase in the film. The molecular structure of 7-tert-butyl-1,3-bis[ $N, N$ bis(4'-methoxyphenyl)amino]pyrene (3e) was unambiguously confirmed by X-ray crystallography. Shown in Figure 1 is the crystal structure of 3e, which shows the dihedral angles between the $\mathrm{C}_{6}$ aromatic rings and the pyrene unit. Unsurprisingly, the $p$-OMe-phenyl groups point in different directions (Figure 1b). The dihedral angles between the pyrene core $(\mathrm{C} 1>\mathrm{C} 16)$ and the $\mathrm{C}_{6}$ aromatic rings are as follows: $75.81(3)^{\circ}(\mathrm{C} 21>\mathrm{C} 26), 79.34(3)^{\circ}(\mathrm{C} 28>\mathrm{C} 33), 60.79(11)^{\circ}(\mathrm{C} 35>$ C40) for the major disorder component, and 81.25(3) ${ }^{\circ}(\mathrm{C} 42>\mathrm{C} 47)$, respectively. The aromatic rings of the diphenylamino unit exhibit a twisted geometry, which, when combined with the bulky tert-butyl 
groups, reduces the $\pi-\pi$ stacking interactions. By comparison, both the phenyl and pyrene units of 3e are involved in two kinds of $\pi$ interactions between adjacent molecules, which results in the formation of a three-dimensional framework (Figure 2a). ${ }^{17}$

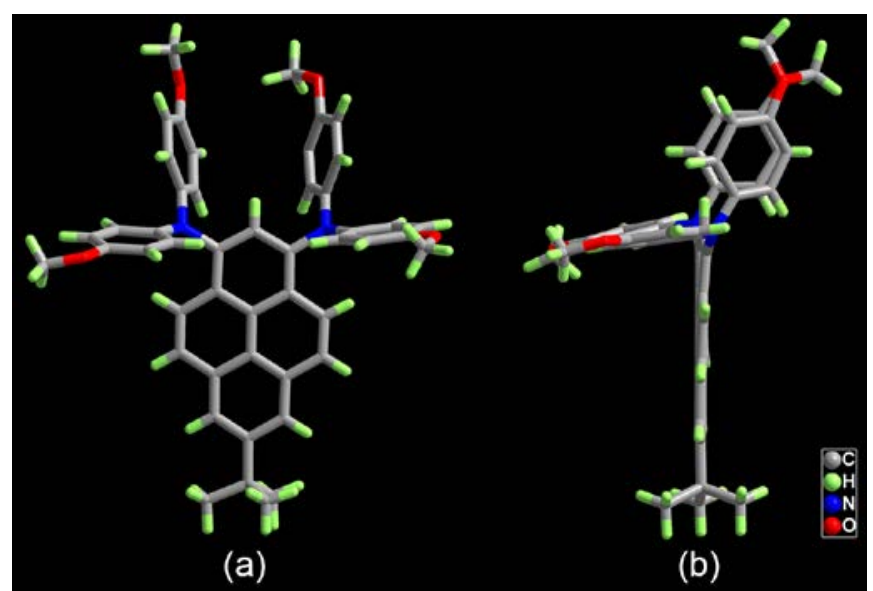

Figure 1. The crystal structure of compound 3e: (a) top view and (b) side view.

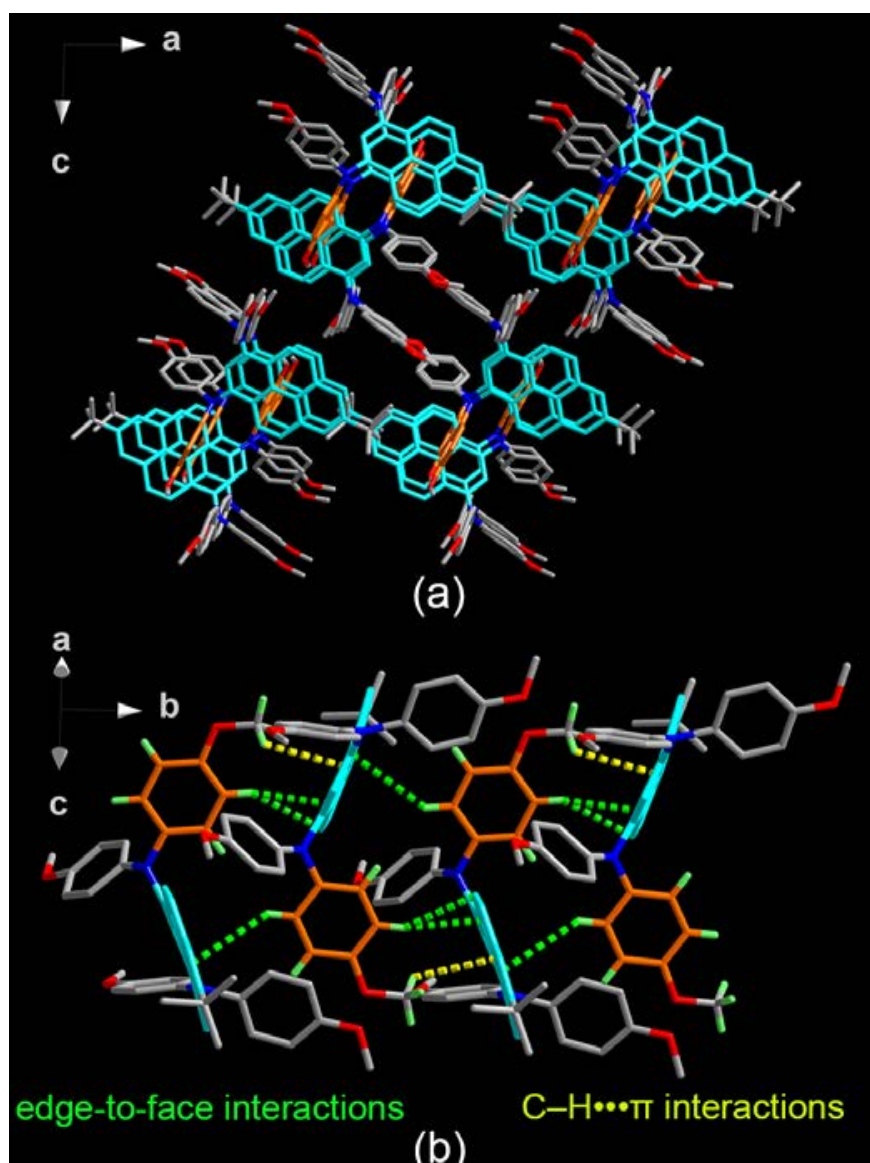

Figure 2. (a) The molecular packing of compound $3 \mathbf{e}$ as viewed parallel to the $b$ axis of the unit cell; (b) the principal intermolecular packing interactions (Most hydrogen atoms are omitted for clarity).

A detailed investigation indicated that two types of $\pi$ interactions were present, namely 1) a $\mathrm{MeC}-\mathrm{H} \cdots \pi$ interaction of the methoxy group with the phenyl unit at a distance of $2.86 \AA$ (yel- 
low dashed lines); and 2) an edge-to-face $\mathrm{ArC}-\mathrm{H} \cdots \pi$ interaction between the edge of the phenyl unit and the face of the pyrene core at a distance in the range 3.56-4.03 $\AA$ (green dashed lines). This interestingly results in a regular arrangement of alternating, anti-parallel stacks (Figure 2b). To be more exact, a compact supramolecular assembly is observed from alternating donor of phenyl groups (orange color) and the pyrene core (blue color) due to weak intermolecular interactions.

Table 1. The physical properties of compounds of type 3a-e.

\begin{tabular}{|c|c|c|c|c|c|c|c|c|c|}
\hline $\mathbf{R}$ & $\begin{array}{c}\lambda_{\text {abs }}(\mathrm{nm}) \\
\text { sol }^{\mathrm{a}}\end{array}$ & $\begin{array}{c}\lambda_{\text {PL }}(\mathrm{nm}) \\
\text { sol }^{\text {a }} / \text { film }^{\mathrm{b}}\end{array}$ & $\begin{array}{c}\log \varepsilon \\
\mathrm{M}^{-1} \cdot \mathrm{cm}^{-1}\end{array}$ & $\begin{array}{c}T_{\mathrm{m}} \\
\left({ }^{\circ} \mathrm{C}\right)^{c}\end{array}$ & $\begin{array}{c}T_{\mathrm{d}} \\
\left({ }^{\circ} \mathrm{C}\right)^{d}\end{array}$ & $\begin{array}{c}\Phi_{\mathrm{PL}}(\%) \\
\text { sol }^{l} / \text { film }^{b} \\
\end{array}$ & $\begin{array}{c}\mathrm{HOMO} \\
(\mathrm{eV})^{e}\end{array}$ & $\begin{array}{l}\text { LUMO } \\
(\mathrm{eV})^{f}\end{array}$ & $E_{\mathrm{g}}(\mathrm{eV})^{g}$ \\
\hline 3a & 294,414 & $465 / 525$ & 4.59 & 198 & 348 & 79/33 & -4.95 & -1.95 & 3.00 \\
\hline $3 \mathbf{b}$ & 299,414 & $467 / 514$ & 4.62 & 238 & 372 & $82 / 46$ & -4.79 & -1.79 & 3.00 \\
\hline 3c & 302,424 & $489 / 494$ & 4.65 & 214 & 383 & $78 / 29$ & -4.65 & -1.72 & 2.93 \\
\hline 3d & 302,425 & $491 / 472$ & 4.61 & 229 & 391 & $57 / 10$ & -4.68 & -1.76 & 2.92 \\
\hline $3 e$ & 301,434 & $525 / 573$ & 4.62 & 262 & 392 & $60 / 24$ & -4.43 & -1.57 & 2.86 \\
\hline
\end{tabular}

These molecular designs were guided by density functional theory (DFT) calculations at the B3LYP/6-31g-(d)) level to examine their lowest unoccupied molecular orbital (LUMO), and highest occupied molecular orbital (HOMO). As depicted in Figure 3, the HOMOs of 3a-e are mainly spread over the diphenylamino moiety and the pyrene core, while the LUMOs are mostly distributed on the pyrene core and slightly extended to the phenyl ring. It is noteworthy that the separated HOMOs and LUMOs are important for high luminescence efficiency of the molecule in certain circumstances, which could increase the potential of Thermally Activated Delayed Fluorescence emitters by adjusting the energy gap. ${ }^{18}$

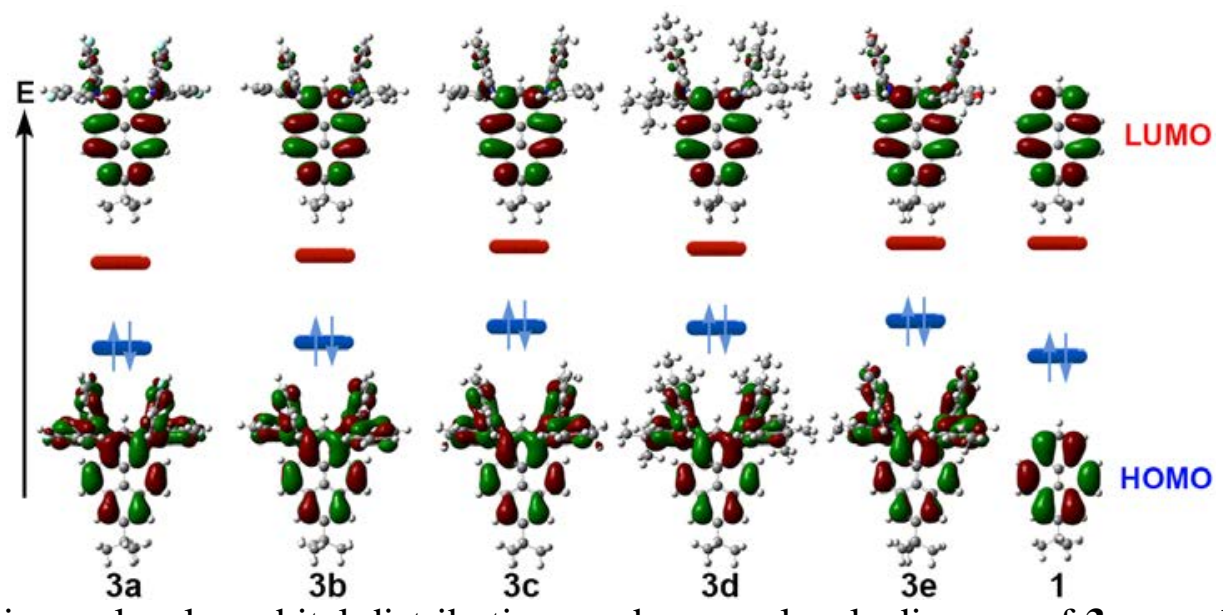

Figure 3. Frontier-molecular-orbital distributions and energy levels diagram of 3a-e and 1 by DFT calculations. 
More and more classical donors and acceptors are attracting interest in the field of organic electronics. Herein, donor functionalized diphenylamines were selected as the hole-transport materials. ${ }^{19}$ The contours of the LUMO and HOMO of compounds 3a-e revealed that the incorporation of a strong electron-donating group on the diphenylamine decreases the contribution of the pyrene core in the HOMOs. The distribution of LUMO orbitals of 3a-e indicated the acceptor nature of the pyrene unit. It is very likely that intramolecular charge-transfer (ICT) states would be formed for these monomers. In this case of the donor appended molecules, the energy gaps were further evaluated. As shown in Table 1 and the energy level diagram Figure 3, the energetic proximity of the low lying LUMO and high lying HOMO results in a reduced energy gap compared with compound $\mathbf{1}^{20}$ The most interesting finding from the DFT calculations is that there is a positive correlation trend between the electronegativity of the functional groups occupying the para position at the phenyl moiety and the HOMO-LUMO gaps, which makes it possible to predict that the monomers 3a-e would have red-shifted absorption spectra. Based on our preliminary theoretical guidance, the steady-state absorption and emission properties were investigated both in solution and in the solid state.
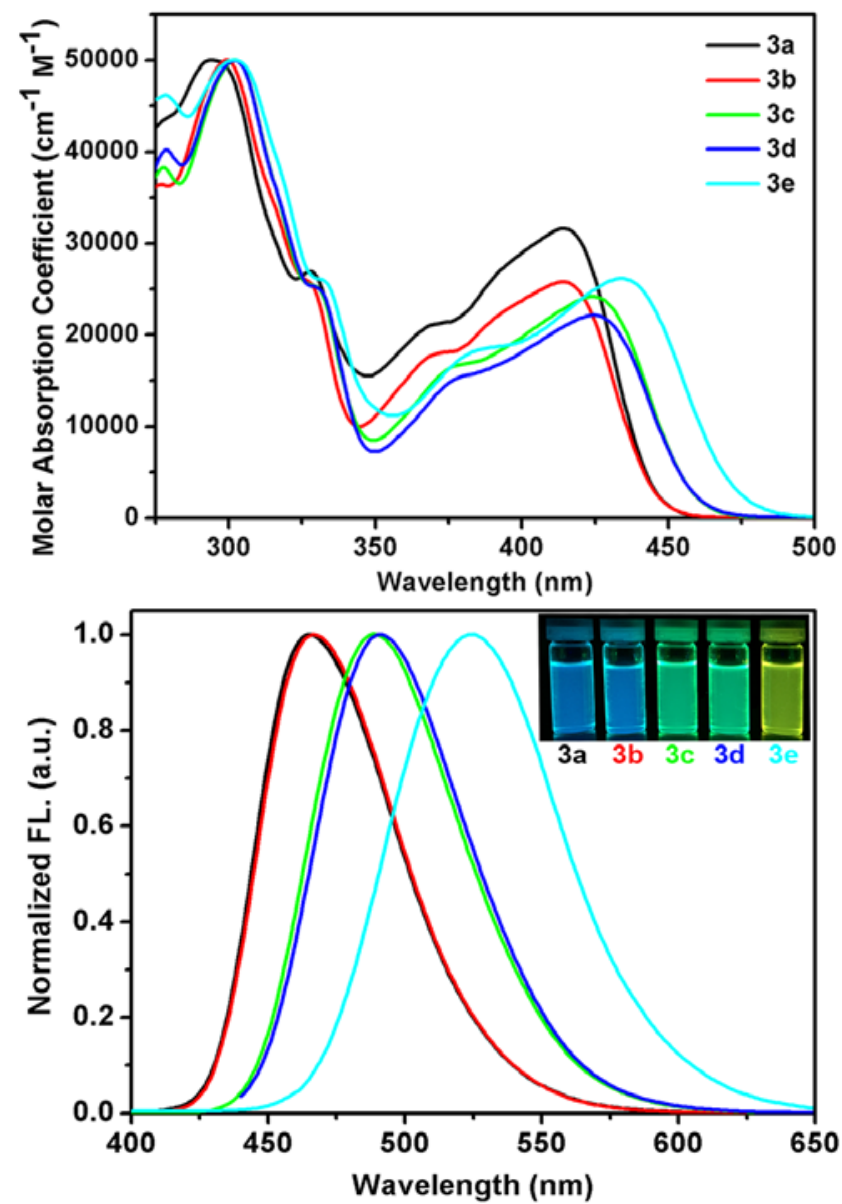

Figure 4. Absorption (top) and emission (bottom) profiles for compounds 3 in $\mathrm{CH}_{2} \mathrm{Cl}_{2}$ solution. 
The absorption and emission spectra of compounds 3a-e both in solution and in the solid state are shown in Figure 4, S11 and summarized in Table 1. As shown in Figure 4 (top), type 3 compounds have a strong, high-energy band centered at 294-302 nm, which is mainly due to the $\pi-\pi^{*}$ transitions of the substituents and pyrene core. In this type of molecule, with classical donor groups at the terminal aromatic rings of pyrene, all of the monomers exhibited a broad absorption band with low-energy absorption (414-434 nm), indicating that their excited states possess some charge transfer (CT) absorption associated with the ICT from the para substituents of the $N, N$-diphenylamine terminal to the pyrene unit, which is attributed to the separated HOMO and LUMO distributions. It was found that the low-energy band is relatively more affected and sensitive than the highenergy band by the nature of the functional groups para to the phenyl moiety according to the molar absorption coefficient (Figure 4 top). Compounds 3a-e have a high-energy band which corresponds to a molar absorption coefficient centered at 48046-50002 $\mathrm{cm}^{-1} \mathrm{M}^{-1}$, and a lowenergy band which corresponds to a molar absorption coefficient ranging from 22135 to 31614 $\mathrm{cm}^{-1} \mathrm{M}^{-1}$. The band gap energy $\left(E_{\mathrm{g}}\right)$ of compounds 3a-e calculated from the absorption edge of the UV/Vis spectra are also summarized in Table 1. The LUMO levels of 3a-e were estimated from the $E_{\mathrm{g}}$ and HOMO levels.

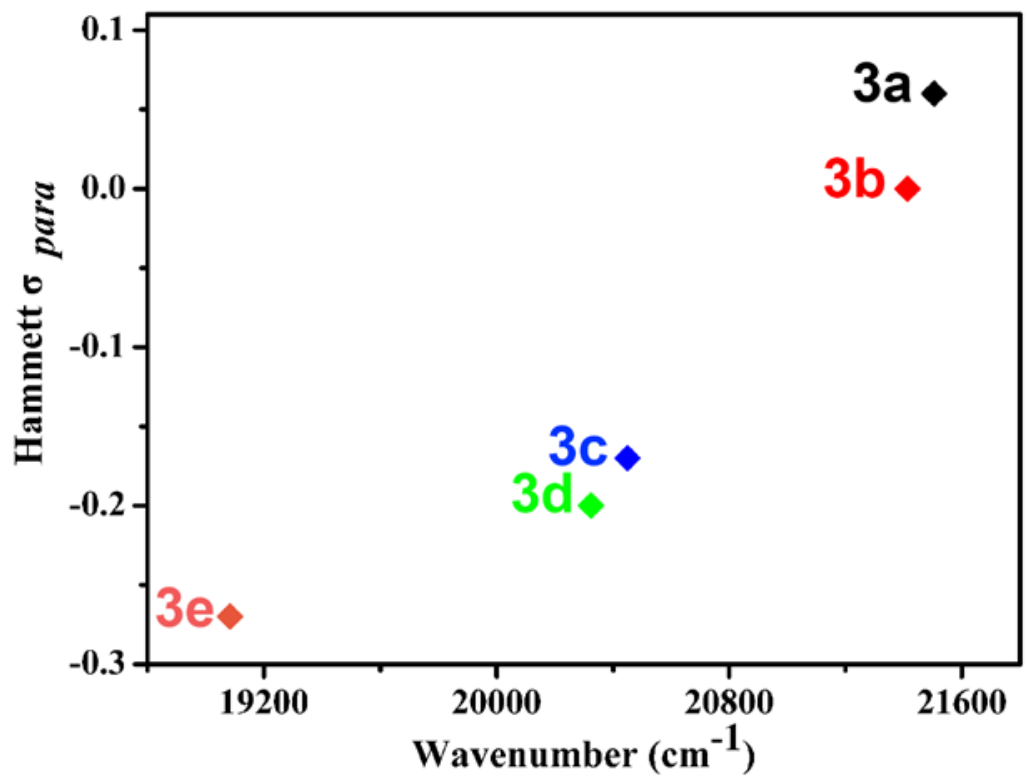

Figure 5. Hammett $\sigma_{\text {para }}$ constants versus wavenumber $\left(\mathrm{cm}^{-1}\right)$ for 3a (black), 3b (red), 3c (blue), 3d (green), and 3e (orange).

The emission maxima of this set of monomers 3 are in the range 465-525 nm in dilute $\mathrm{CH}_{2} \mathrm{Cl}_{2}$ solutions with a systematic bathochromic shift in the order $\mathbf{3 a}<\mathbf{3 b}<\mathbf{3} \mathbf{c}<\mathbf{3 d}<\mathbf{3 e}$ (Figure 4 bottom), consistent with the electronegativity of the substituents at the para position of the phenyl moiety. These results, combined with the theoretical calculations, indicate that the energy gap $\left(E_{\mathrm{g}}\right)$ could be tuned be- 
tween the group and the excited states by introducing different substituent groups. More interestingly, when the $\lambda_{\text {em max }}$ are converted to wavenumbers $\left(\mathrm{cm}^{-1}\right)$ and plotted versus the Hammett $\sigma_{\text {para }}$ constants for the functional groups para on the phenyl, a positive correlation was clearly observed obviously (Figure 5). This result establishes a promising strategy for the design of pyrene-based luminophores by choosing functional groups on the basis of their Hammett $\sigma_{\text {para }}$ value.

The emission spectra in the solid state were also recorded, and all of the compounds were found to exhibit a red shift trend compared with their corresponding emission spectra in solution (Table 1, and Figure S12). However, the emission band maxima of 3d was blue-shifted (19 $\mathrm{nm}$ ) relative to the results in solution, because of the introduction of the bulky electron donor tert-butyl group that not only plays a role in restricting aggregation in the solid state but also affects the conformation of the electronic structures. It was observed that the quantum yields showed no trend in solution. Additionally, a decrease in the photoluminescence quantum yield of these compounds was observed in thin films. In order to gain further insight into the pronounced difference of luminescence quantum efficiency in both these two states, $H$ - and $J$-aggregates ${ }^{21}$ were elucidated since it is generally agreed that these are the best known theoretical predictors (Figure 6). According to the optical results, we assumed that these molecules may aggregate in a parallel way (face-to-face stacking) to form a sandwich-type arrangement (H-dimer), which is also consistent with the crystallization results. Furthermore, an important feature of the $H$ aggregate of the dimer is that the fluorescence is quenched, as the lowest excited energy level is forbidden.

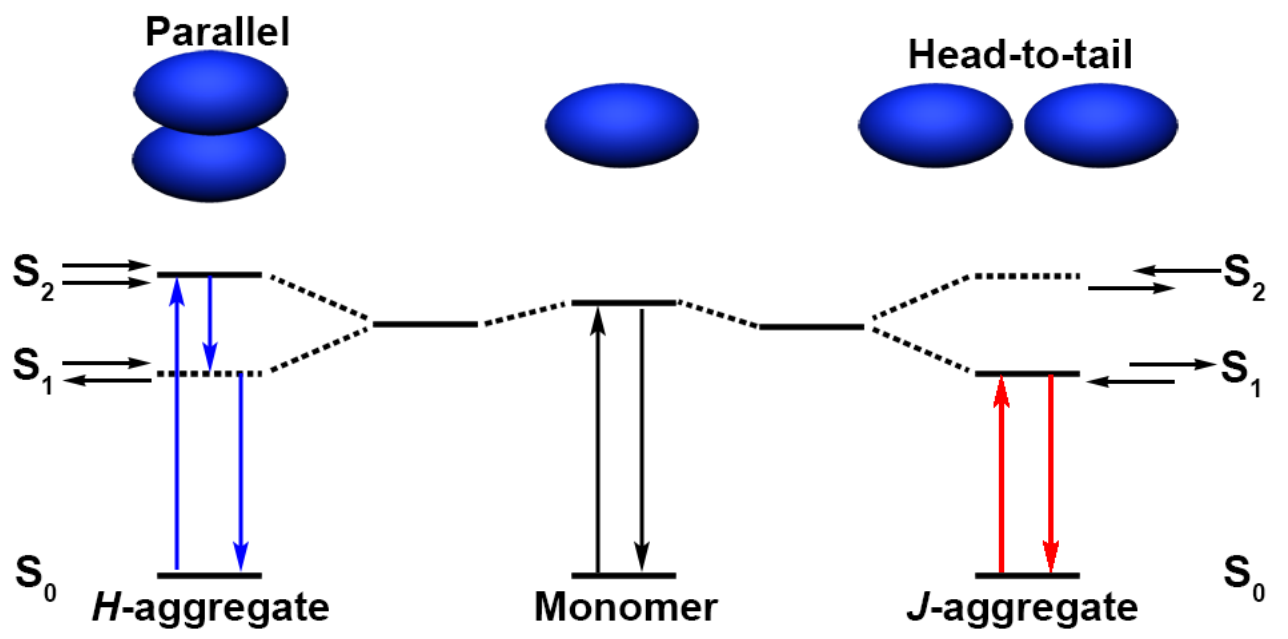

Figure 6. Schematic representation of the relationship between chromophore arrangement based on the molecular exciton theory. 

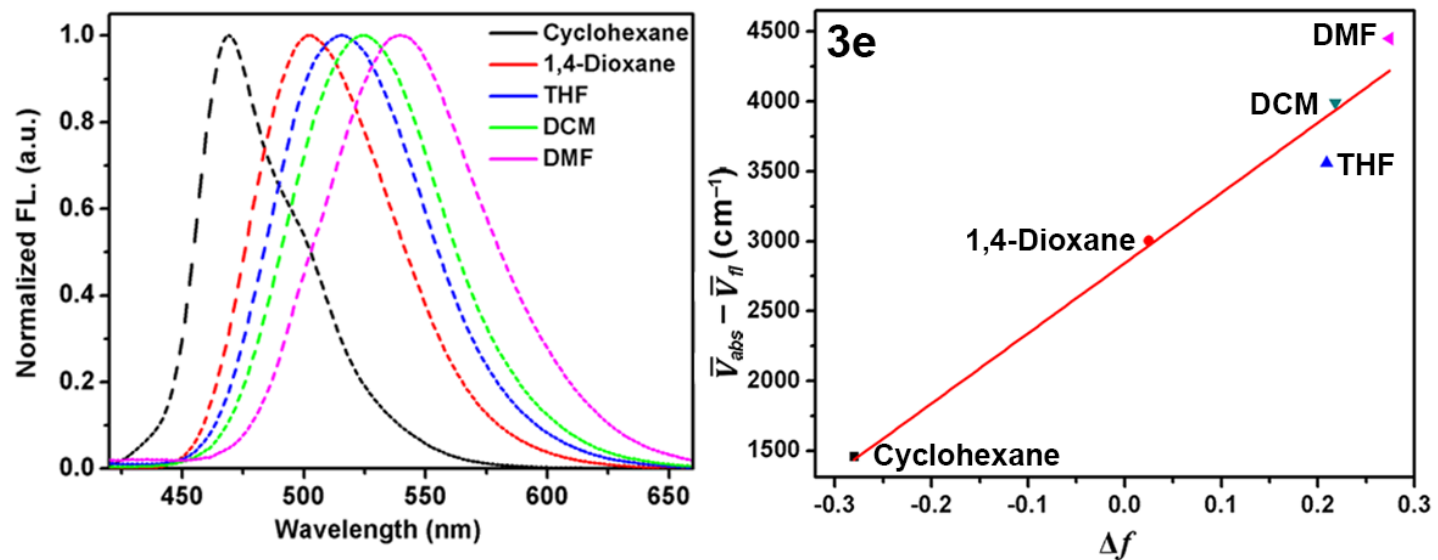

Figure 7. (left) Emission spectra of $3 \mathbf{e}$ in cyclohexane, 1,4-dioxane, THF, DCM, and DMF at room temperature; (right) Lippert-Mataga plots for compound 3e.

The fluorescence spectra of 3a-e are highly sensitive toward the solvent polarity. The spectral properties of the solvatochromism were investigated in different solvents with varying polarity (cyclohexane, 1,4-dioxane, tetrahydrofuran, dichloromethane, and dimethyl formamide); the results are shown in the Supporting Information (Figure S12). Compound 3e is a representative example, for which Figure 7 (left) shows a significant red-shift on increasing the solvent polarity from cyclohexane to DMF (47 nm for 3a, $43 \mathrm{~nm}$ for 3b, $54 \mathrm{~nm}$ for 3c, $54 \mathrm{~nm}$ for 3d, $71 \mathrm{~nm}$ for 3e, respectively). This phenomenon was further evaluated by the relationship between the Stokes shifts in various solvents and the Lippert equation, $^{22}$ which shows a linear correlation between these two factors (Figure 7 right). The trend in the slope of the Lippert-Mataga plots follow the order $\mathbf{3 e}>\mathbf{3 d}>\mathbf{3} \mathbf{c}>\mathbf{3 b} \approx \mathbf{3} \mathbf{a}$, and we can find that the value of the slope of the fitting line for $\mathbf{3 e}$ (5021.5) is higher than that for $\mathbf{3 b}$ (3502.4), indicating the intramolecular excited state with a larger dipolar moment for the former than the latter. Also, those results reveal extraordinary sensitivity to solvent polarity. Moreover, the distinct charge separation and higher dipole moment were further confirmed in the excited state. ${ }^{23}$

\section{CONCLUSIONS}

In summary, a series of tuneable pyrene-based monomers 3a-e were designed and synthesized by a facile strategy, and their optical properties were investigated both experimentally and computationally. It was determined that these systems exhibited predictable photophysical properties by introducing different substituents at the para position of the phenyl moieties. Moreover, a positive correlation between the wavelength of the $\lambda_{\mathrm{em} \max }$ and the Hammett $\sigma_{\text {para }}$ constants for the functional groups provided evidence that these systems may be used to tune the emission color from blue to yellow or orange, and further investigations aimed at developing these optoelectronic materials for practical applications are ongoing in our group. 


\section{EXPERIMENTAL SECTION}

All melting points (Yanagimoto MP-S1) are uncorrected. ${ }^{1} \mathrm{H}$ NMR spectra (300 MHz) were recorded on a Nippon Denshi JEOL FT-300 NMR spectrometer with $\mathrm{SiMe}_{4}$ as an internal reference: $J$-values are given in Hz. IR spectra were measured for samples as KBr pellets in a Nippon Denshi JIR-AQ2OM spectrophotometer. UV-vis spectra were recorded on a Perkin Elmer Lambda 19 UV/VIS/NIR spectrometer. Mass spectra were obtained on a Nippon Denshi JMS-01SA-2 spectrometer at 75 eV using a direct-inlet system.

\section{Materials}

Unless otherwise stated, all other reagents used were purchased from commercial sources and were used without further purification. The preparations of 2-tert-butylpyrene (1) and 7-tert-butyl-1,3dibromopyrene (2) were described previously. ${ }^{24}$

\section{Synthetic Procedures}

\section{Synthesis of 7-tert-butyl-1,3-bis( $N, N$-bis(4'-fluorophenyl)amino)pyrene (3a)}

A mixture of 7-tert-butyl-1,3-dibromopyrene 2 (300 mg, $0.72 \mathrm{mmol}$ ), bis(4-fluorophenyl)amine (443 $\mathrm{mg}, 2.16 \mathrm{mmol})$, palladium(II) acetate $(8.1 \mathrm{mg}, 36 \mu \mathrm{mol})$, sodium tert-butoxide (416 mg, $4.33 \mathrm{mmol}$ ), and tri-tert-butylphosphine $(1 \mathrm{M}$ in toluene, $0.07 \mathrm{~mL}, 70 \mu \mathrm{mol})$ in toluene $(15 \mathrm{~mL})$ was heated to reflux for $12 \mathrm{~h}$ under argon. The mixture was chilled to room temperature and quenched with water (100 mL). The mixture was extracted with dichloromethane $(3 \times 50 \mathrm{~mL})$, and the combined extracts were washed with water and brine, dried with $\mathrm{MgSO}_{4}$ and concentrated. The residue was chromatographed over silica gel (Wako C-300, 200 g) with chloroform:hexane (2:8) as eluent to give an orange solid. Recrystallization from methanol afforded 7-tert-butyl-1,3-bis( $N, N$-bis(4'-fluorophenyl)amino)pyrene 3a (368 mg, $77 \%$ ) as orange prisms. M.p. $198-200^{\circ} \mathrm{C} ;{ }^{1} \mathrm{H}$ NMR $\left(300 \mathrm{MHz}, \mathrm{CDCl}_{3}\right): \delta_{\mathrm{H}}=1.53(\mathrm{~s}, 9 \mathrm{H}, t \mathrm{Bu}), 6.85-$ 6.97 (m, 16H, Ar- $H$ ), 7.47 (s, 1H, pyrene-H), 7.88 (d, $J=9.2 \mathrm{~Hz}, 2 \mathrm{H}$, pyrene-H), 8.00 (d, $J=9.2 \mathrm{~Hz}$, 2H, pyrene-H), 8.13 ppm (s, 2H, pyrene-H); ${ }^{13} \mathrm{C}$ NMR (100 MHz, $\left.\mathrm{CDCl}_{3}\right): \delta_{\mathrm{C}}=31.8,35.2,115.9,116.1$, 122.8, 123.2, 123.2, 126.0, 127.7, 127.8, 128.0, 131.0, 141.6, 144.7, 144.7, 150.0, 156.9, 159.3 ppm; FAB-MS: $m / z$ calcd for $\mathrm{C}_{44} \mathrm{H}_{32} \mathrm{~F}_{4} \mathrm{~N}_{2} 664.2502\left[\mathrm{M}^{+}\right]$; found $664.1047\left[\mathrm{M}^{+}\right]$.

\section{Synthesis of 7-tert-butyl-1,3-bis( $N, N$-diphenylamino)pyrene (3b)}

A mixture of 7-tert-butyl-1,3-dibromopyrene 2 (300 mg, $0.72 \mathrm{mmol}$ ), diphenylamine 2 (366 mg, 2.16 mmol), palladium(II) acetate $(8.1 \mathrm{mg}, 36 \mu \mathrm{mol})$, sodium tert-butoxide (416 mg, $4.33 \mathrm{mmol})$, and tritert-butylphosphine (1M in toluene, $0.07 \mathrm{~mL}, 70 \mu \mathrm{mol})$ in toluene $(15 \mathrm{~mL})$ was heated to reflux for $12 \mathrm{~h}$ under argon. The mixture was chilled to room temperature and quenched with water (100 mL). The mixture was extracted with dichloromethane $(3 \times 50 \mathrm{~mL})$, and the combined extracts were washed with 
water and brine, dried with $\mathrm{MgSO}_{4}$ and concentrated. The residue was chromatographed over silica gel (Wako C-300, 200 g) with chloroform:hexane (2:8) as eluent to give a light-yellow solid. Recrystallization from ethyl acetate afforded 7-tert-butyl-1,3-bis( $N, N$-diphenylamino)pyrene $3 \mathbf{b}$ (291 mg, 68\%) as light yellow prisms. M.p. 235-236 ${ }^{\circ} \mathrm{C} ;{ }^{1} \mathrm{H}$ NMR (300 MHz, $\left.\mathrm{CDCl}_{3}\right): \delta_{\mathrm{H}}=1.53(\mathrm{~s}, 9 \mathrm{H}, t \mathrm{Bu}), 6.90(\mathrm{t}, J=$ $7.2 \mathrm{~Hz}, 4 \mathrm{H}, \mathrm{Ar}-H$ ), 7.04 (d, $J=7.5 \mathrm{~Hz}, 8 \mathrm{H}, \mathrm{Ar}-H$ ), 7.16 (d, $J=8.0 \mathrm{~Hz}, 8 \mathrm{H}, \mathrm{Ar}-H$ ), 7.67 (s, 1H, pyrene$H$ ), 7.86 (d, $J=9.2 \mathrm{~Hz}, 2 \mathrm{H}$, pyrene- $H$ ), 8.06 (d, $J=9.2 \mathrm{~Hz}, 2 \mathrm{H}$, pyrene- $H$ ), 8.10 ppm (s, 2H, pyrene- $H$ ); ${ }^{13} \mathrm{C}$ NMR $\left(100 \mathrm{MHz} \mathrm{CDCl}_{3}\right): \delta_{\mathrm{C}}=31.8,35.2,121.7,121.8,122.5,123.1,123.2,126.8,127.7,127.9$, 129.1, 129.2, 131.1, 141.5, 148.3, 149.8 ppm; FAB-MS: m/z calcd for $\mathrm{C}_{44} \mathrm{H}_{36} \mathrm{~N}_{2} 592.2878$ [M ${ }^{+}$; found $592.2581\left[\mathrm{M}^{+}\right]$.

\section{Synthesis of 7-tert-butyl-1,3-bis( $N, N$-bis(4'-methylphenyl)amino)pyrene (3c)}

A mixture of 7-tert-butyl-1,3-dibromopyrene 2 (300 mg, 0.72 mmol), bis(4-methylphenyl)amine (426 mg, $2.16 \mathrm{mmol})$, palladium(II) acetate $(8.1 \mathrm{mg}, 36 \mu \mathrm{mol})$, sodium tert-butoxide (416 mg, $4.33 \mathrm{mmol})$, and tri-tert-butylphosphine $(1 \mathrm{M}$ in toluene, $0.07 \mathrm{~mL}, 70 \mu \mathrm{mol})$ in toluene $(15 \mathrm{~mL})$ was heated to reflux for $12 \mathrm{~h}$ under argon. The mixture was chilled to room temperature and quenched with water (100 mL). The mixture was extracted with dichloromethane $(3 \times 50 \mathrm{~mL})$, and the combined extracts were washed with water and brine, dried with $\mathrm{MgSO}_{4}$ and concentrated. The residue was chromatographed over silica gel (Wako C-300, 200 g) with chloroform:hexane (2:8) as eluent to give a light-yellow solid. Recrystallization from ethyl acetate afforded 7-tert-butyl-1,3-bis( $N, N$-bis(4'-methylphenyl)amino)pyrene $3 c$ (387 mg, 82\%) as light-yellow prisms. M.p. $224-225^{\circ} \mathrm{C} ;{ }^{1} \mathrm{H}$ NMR (300 MHz, $\left.\mathrm{CDCl}_{3}\right)$ : $\delta_{\mathrm{H}}=1.52$ (s, 9H, $\left.t \mathrm{Bu}\right)$, 2.25 (s, 12H, Me), 6.91 (d, $J=8.8 \mathrm{~Hz}, 8 \mathrm{H}, \mathrm{Ar}-H$ ), 6.96 (d, $J=8.4 \mathrm{~Hz}, 8 \mathrm{H}, \mathrm{Ar}-H$ ), 7.60 (s, 1H, pyrene$H$ ), 7.83 (d, $J=9.2 \mathrm{~Hz}, 2 \mathrm{H}$, pyrene- $H$ ), 8.06 (d, $J=9.7 \mathrm{~Hz}, 2 \mathrm{H}$, pyrene-H), 8.07 ppm (s, 2H, pyrene- $H$ ); ${ }^{13} \mathrm{C}$ NMR $\left(100 \mathrm{MHz}, \mathrm{CDCl}_{3}\right): \delta_{\mathrm{C}}=20.7,31.8,35.1,121.7,122.3,123.3,126.4,127.2,127.9,128.9$, 129.6, 130.8, 131.1, 142.0, 146.2, 149.6 ppm; FAB-MS: $\mathrm{m} / \mathrm{z}$ calcd for $\mathrm{C}_{48} \mathrm{H}_{44} \mathrm{~N}_{2} 648.3504$ [M ${ }^{+}$; found $648.3521\left[\mathrm{M}^{+}\right]$.

\section{Synthesis of 7-tert-butyl-1,3-bis( $N, N$-bis(4’-tert-butylphenyl)amino)pyrene (3d)}

A mixture of 7-tert-butyl-1,3-dibromopyrene 2 (300 mg, $0.72 \mathrm{mmol}$ ), bis(4-tert-butylphenyl)amine (607 mg, $2.16 \mathrm{mmol})$, palladium(II) acetate $(8.1 \mathrm{mg}, 36 \mu \mathrm{mol})$, sodium tert-butoxide (416 mg, 4.33 mmol), and tri-tert-butylphosphine (1M in toluene, $0.07 \mathrm{~mL}, 70 \mu \mathrm{mol})$ in toluene $(15 \mathrm{~mL})$ was heated to reflux for $12 \mathrm{~h}$ under argon. The mixture was chilled to room temperature and quenched with water (100 $\mathrm{mL})$. The mixture was extracted with dichloromethane $(3 \times 50 \mathrm{~mL})$, and the combined extracts were washed with water and brine, dried with $\mathrm{MgSO}_{4}$ and concentrated. The residue was chromatographed over silica gel (Wako C-300, 200 g) with chloroform:hexane (3:7) as eluent to give an orange solid. Recrystallization from methanol afforded 7-tert-butyl-1,3-bis( $N, N$-bis(4'-tert-butylphenyl)amino)pyrene 
3d (588 mg, 73\%) as yellow prisms. M.p. 229-230 ${ }^{\circ}$; ${ }^{1} \mathrm{H}$ NMR (300 $\left.\mathrm{MHz}, \mathrm{CDCl}_{3}\right): \delta_{\mathrm{H}}=1.27(\mathrm{~s}, 18 \mathrm{H}$, $t \mathrm{Bu}$ ), 1.29 (s, 9H, $t \mathrm{Bu}), 6.99$ (t, $J=8.1 \mathrm{~Hz}, 7 \mathrm{H}, \operatorname{Ar}-H), 7.07$ (d, $J=7.6 \mathrm{~Hz}, 2 \mathrm{H}, \operatorname{Ar}-H), 7.18$ (t, $J=8.1$ Hz, 7H, Ar- $H$ ), 7.75 (d, $J=7.6$ Hz, 1H, pyrene- $H$ ), 7.86 (t, $J=8.6 \mathrm{~Hz}, 2 \mathrm{H}$, pyrene- $H), 8.10 \mathrm{ppm}(\mathrm{m}, 4 \mathrm{H}$, pyrene- $H) ;{ }^{13} \mathrm{C}$ NMR $\left(100 \mathrm{MHz} \mathrm{CDCl}_{3}\right): \delta_{\mathrm{C}}=31.4,31.8,34.1,35.1,121.0,122.3,123.2,123.4,125.8$, 126.9, 127.3, 127.9, 128.9, 129.3, 131.1, 134.7, 141.7, 144.1, 145.7, 149.6 ppm; FAB-MS: m/z calcd for $\mathrm{C}_{60} \mathrm{H}_{68} \mathrm{~N}_{2} 816.5383\left[\mathrm{M}^{+}\right]$; found $816.5383\left[\mathrm{M}^{+}\right]$.

\section{Synthesis of 7-tert-butyl-1,3-bis( $N, N$-bis(4'-methoxyphenyl)amino)pyrene (3e)}

A mixture of 7-tert-butyl-1,3-dibromopyrene 2 (300 mg, $0.72 \mathrm{mmol}$ ), bis(4-methoxyphenyl)amine (495 mg, $2.16 \mathrm{mmol}$ ), palladium(II) acetate (8.1 mg, $36 \mu \mathrm{mol})$, sodium tert-butoxide (416 mg, 4.33 $\mathrm{mmol})$, and tri-tert-butylphosphine (1M in toluene, $0.07 \mathrm{~mL}, 70 \mu \mathrm{mol})$ in toluene $(15 \mathrm{~mL})$ was heated to reflux for $12 \mathrm{~h}$ under argon. The mixture was chilled to room temperature and quenched with water (100 $\mathrm{mL})$. The mixture was extracted with dichloromethane $(3 \times 50 \mathrm{~mL})$, and the combined extracts were washed with water and brine, dried with $\mathrm{MgSO}_{4}$ and concentrated. The residue was chromatographed over silica gel (Wako C-300, 200 g) with chloroform:hexane (8:2) as eluent to give an orange solid. Recrystallization from ethyl acetate afforded 7-tert-butyl-1,3-bis( $N, N$-bis(4'-methoxyphenyl)amino)pyrene 3e (370 mg, 72\%) as orange prisms. M.p. 260-261 ${ }^{\circ} \mathrm{C} ;{ }^{1} \mathrm{H}$ NMR $\left(300 \mathrm{MHz}, \mathrm{CDCl}_{3}\right): \delta_{\mathrm{H}}=1.52(\mathrm{~s}, 9 \mathrm{H}$, $t \mathrm{Bu}), 3.74$ (s, 12H, OMe), 6.72 (d, $J=9.2 \mathrm{~Hz}, 8 \mathrm{H}, \mathrm{Ar}-H), 6.92$ (d, $J=9.0 \mathrm{~Hz}, 8 \mathrm{H}, \mathrm{Ar}-H), 7.48$ (s, $1 \mathrm{H}$, pyrene- $H$ ), 7.80 (d, $J=9.3 \mathrm{~Hz}, 2 \mathrm{H}$, pyrene- $H$ ), 8.04 (d, $J=8.4 \mathrm{~Hz}, 2 \mathrm{H}$, pyrene- $H$ ), 8.06 ppm (s, 2H, pyrene-H); ${ }^{13} \mathrm{C}$ NMR (100 $\left.\mathrm{MHz}, \mathrm{CDCl}_{3}\right): \delta_{\mathrm{C}}=31.8,35.1,55.5,114.5,122.1,123.2,123.3,123.4,125.3$, 126.8, 127.6, 128.0, 131.2, 142.5, 142.7, 149.5, 154.5 ppm; FAB-MS: m/z calcd for $\mathrm{C}_{48} \mathrm{H}_{44} \mathrm{~N}_{2} \mathrm{O}_{4}$ $712.3301\left[\mathrm{M}^{+}\right]$; found $712.3286\left[\mathrm{M}^{+}\right]$.

\section{X-ray Crystallography}

A suitable single crystal $\left(0.87 \times 0.63 \times 0.43 \mathrm{~mm}^{3}\right)$ was selected and mounted on a Bruker APEX 2 CCD diffractometer equipped with graphite-monochromated Mo-Ka radiation for $3 \mathbf{e} .^{25}$ Data were corrected for Lorentz and polarisation effects and for absorption. ${ }^{25}$ The structure was solved by direct methods and refined routinely except that atoms C36 > C41 \& O(3) were modelled as disordered over two sets of positions with major component 51.3(3)\%. Details of the crystal parameters, data collection conditions, and refinement parameters ${ }^{26}$ for the compound $\mathbf{3 e}$ are summarized in Tables S1-2. Crystallographic data for the structure in this paper have been deposited with the Cambridge Crystallographic Data Centre as supplementary publication number CCDC 1537633. Copies of the data can be obtained, free of charge, on application to CCDC, 12 Union Road, Cambridge CB2 1EZ, UK [fax: 144-1223336033 or e-mail: deposit@ccdc.cam.ac.uk]. 


\section{ASSOCIATED CONTENT}

\section{Supporting Information}

The Supporting Information is available free of charge on the ACS Publications website at DOI: 10.1021/acs.joc.Xxxxxxx.

NMR spectra, UV-vis spectra, emission spectra (PDF)

Crystallographic information for $\mathbf{3 e}$ (cif)

\section{AUTHOR INFORMATION}

\section{Corresponding Author}

* E-mail: yamatot@cc.saga-u.ac.jp.

* E-mail: hyxhn@sina.com

\section{Notes}

The authors declare no competing financial interest.

\section{ACKNOWLEDGMENT}

This work was performed under the Cooperative Research Program of "Network Joint Research Center for Materials and Devices (Institute for Materials Chemistry and Engineering, Kyushu University)”. We would like to thank the OTEC at Saga University and the International Cooperation Projects of Guizhou Province (No. 20137002), The EPSRC is thanked for an overseas travel grant to C.R.

\section{REFERENCES}

1 (a) Functional Organic Materials - Syntheses, Strategies, and Applications, Müller, T. J. J., Bunz, U. H. F., Ed.; WileyVHC: Weinheim, 2007. (b) Zhu, M.; Yang, C. Chem. Soc. Rev. 2013, 42, 4963-4976. (c) Maggini, L.; Bonifazi, D. Chem. Soc. Rev. 2012, 41, 211-241. (d) Reineke, S.; Rosenow, T. C.; Lüssem, B.; Leo, K. Adv. Meter. 2010, 22, 3189-3193. (e) Fan, C.; Zhu, L.; Liu, T.; Jiang, B.; Ma, D.; Qin, J.; Yang, C. Angew. Chem., Int. Ed. 2014, 53, 2147-2151.

2 (a) Kido, J.; Okamoto, Y. Chem. Rev. 2002, 102, 2357-2368. (b) Samuel, I. D. W.; Turnbull, G. A. Chem. Rev. 2007, 107, 1272-1295. (c) Grimsdale, A. C.; Leok Chan, K.; Martin, R. E.; Jokisz, P. G.; Holmes, A. B. Chem. Rev. 2009, 109, 897-1091.

3 (a) Stender, A. S.; Marchuk, K.; Liu, C.; Sander, S.; Meyer, M. W.; Smith, E. A.; Neupane, B.; Wang, G.; Li, J.; Cheng, J.-X.; Huang, B.; Fang, N. Chem. Rev. 2013, 113, 2469-2527. (b) Wang, X. H.; Guo, Z. Q.; Zhu, S. Q.; Liu, Y. J.; Shi, P.; Tian, H.; Zhu, W. H. J. Mater. Chem. B 2016, 4, 4683-4689. 
4 (a) Zhang, R.; Zhao, Y.; Zhang, T. F.; Xu, L.; Ni, Z. H. Dyes Pigments 2016, 130, 106-115. (b) Lee, S. Y.; Yasuda, T.; Yang, Y. S.; Zhang, Q. S.; Adachi, C. Angew. Chem., Int. Ed. 2014, 53, 6402-6406. (c) Han, M. G.; Park, K. -B.; Bulliard, X.; Lee, G. H.; Yun, S.; Leem, D. -S.; Heo, C. J.; Yagi, T.; Sakurai, R.; Ro, T.; Lim, S. -J.; Sul, S.; Na, K.; Ahn, J.; Jin, Y. W.; Lee, S. ACS Appl. Mater. Interfaces 2016, 8, 26143-26151.

5 (a) Shen, X.; Wang, Y.; Zhao, E.; Yuan, W.; Liu, Y.; Lu, P.; Qin, A.; Ma, Y.; Sun, J.; Tang, B. Z. J. Phys. Chem. C 2013, 117, 7334-7347. (b) Xue, v; Liu, W.; Qiu, X.; Gao, Y.; Yang, W. J. Phys. Chem. C 2014, 118, 18668-18675.

6 (a) Zhu, L. M.; Xu, J. C.; Sun, Z.; Fu, B. Q.; Qin, C. Q.; Zeng, L. T.; Hu, X. C. Chem. Commun. 2015, 51, 1154-1156. (b) Teran, N. B.; He, G. S.; Baev, A.; Shi, Y. R.; Swihart, M. T.; Prasad, P. N.; Marks, T. J.; Reynolds, J. R. J. Am. Chem. Soc. 2016, 138, 6975-6984.

7 Saigusa, H.; Lim, E. C. Acc. Chem. Res. 1996, 29, 171-178.

8 Hsieh, C. C.; Jiang, C. M.; Chou, P. T. Acc. Chem. Res. 2010, 43, 1364-1374.

9 Levi, L.; Müller, T. J. J. Chem. Soc. Rev. 2016, 45, 2825-2846.

10 (a) Khramov, D. M.; Bielawski, C. W. J. Org. Chem. 2007, 72, 9407-9417. (b) Feng, X.; Tomiyasu, H.; Hu, J. Y.; Wei, X. F.; Redshaw, C.; Elsegood, M. R.J.; Horsburgh, L.; Teat, S. J.; Yamato, T. J. Org. Chem. 2015, 80, 10973-10978. (c) McNamara, L. E.; Liyanage, N.; Peddapuram, A.; Murphy, J. S.; Delcamp, J. H.; Hammer, N. I. J. Org. Chem. 2016, 81, 32-42.

11 Figueira-Duarte, T. M.; Müllen, K. Chem. Rev. 2011, 111, 7260-7314.

12 Misra, R.; Gautam, P.; Mobin, S. M. J. Org. Chem. 2013, 78, 12440-12452.

13 (a) Oseki, Y.; Fujitsuka, M.; Sakamoto, M.; Majima, T. J. Phys. Chem. A 2007, 111, 9781-9788. (b) Yang, S. W.; Elangovan, A.; Hwang, K. C.; Ho, T. I. J. Phys. Chem. B 2005, 109, 16628-16635. (c) Sessler, J. L.; Karnas, E.; Kim, S. K.; Ou, Z. P.; Zhang, M.; Kadish, K. M.; Ohkubo, K.; Fukuzumi, S. J. Am. Chem. Soc. 2008, 130, 15256-15257.

14 Feng, X.; Hu, J. Y.; Redshaw, C.; Yamato, T. Chem. Eur. J. 2016, 22, 11898-11916.

15 Jérome, D.; Schulz, H. J. Advances in Physics 2002, 51, 293-479.

16 (a) Xiao, L. X.; Chen, Z. J.; Qu, B.; Luo, J. X.; Kong, S.; Gong, Q. H.; Kido, J. Adv. Mater. 2011, 23, 926-952. (b) Ying, L.; Ho, C-L.; Wu, H. B.; Cao, Y.; Wong, W-Y. Adv. Mater. 2014, 26, 2459-2473.

17 (a) Xia, H.; Liu, D. Q.; Song, K. S.; Miao, Q. Chem. Sci. 2011, 2, 2402-2406. (b) Wang, C. Z.; Kihara, R.; Feng. X.; Thuéry, P.; Redshaw, C.; Yamato, T. ChemistrySelect 2017, 2, $1436-1441$. 
18 (a) Shizu, K.; Tanaka, H.; Uejima, M.; Sato, T.; Tanaka, K.; Kaji, H.; Adachi, C. J. Phys. Chem. C 2015, 119, 1291-1297. (b) Rajamalli, P.; Senthilkumar, N.; Gandeepan, P.; Huang, P. Y.; Huang, M. J.; Ren-Wu, C. Z.; Yang, C. Y.; Chiu, M. J.; Chu, L. K.; Lin, H. W.; Cheng, C. H. J. Am. Chem. Soc. 2016, 138, 628-634.

19 Sasabe, H.; Kido, J. J. Mater. Chem. C 2013, 1, 1699-1707.

20 Feng, X.; Hu, J. Y.; Tomiyasu, H.; Tao, Z.; Redshaw, C.; Elsegood, M. R. J.; Horsburgh, L.; Teat, S. J.; Wei, X. F.; Yamato, T. RSC Adv. 2015, 5, 8835-8848.

21 (a) Jelley, E. E. Nature 1936, 138, 1009-1010. (b) Kasha, M.; Rawls, H. R.; Ashraf ElBayoumi, M. Pure Appl. Chem. 1965, 11, 371-392. (c) Lanzani, G. Photophysics Behind Photovoltaics and Photonics Wiley, 2002. (d) Heyne, B. Photochem. Photobiol. Sci. 2016, 15, 11031114.

22 (a) Lippert, V. E.; Z. Naturforsch. A: Phys. Sci. 1955, 10, 541-545. (b) Mataga, N.; Kaifu, Y.; Koizumi, M. Bull. Chem. Soc. Jpn. 1956, 29, 465-470.

23 (a) Jadhav, T.; Dhokale, B.; Patil, Y.; Mobin, S. M.; Misra, R. J. Phys. Chem. C 2016, 120, 24030-24040. (b) Tayade, R. P.; Sekar, N. J. Lumin. 2016, 176, 298-308. (c) Lim, C-H.; Ryan, M. D.; McCarthy, B. G.; Theriot, J. C.; Sartor, S. M.; Damrauer, N. H.; Musgrave, C. B.; Miyake, G. M. J. Am. Chem. Soc. 2017, 139, 348-355.

24 Feng, X.; Hu, J. Y.; Yi, L.; Seto, N.; Tao, Z.; Redshaw, C.; Elsegood, M. R. J.; Yamato, T. Chem. - Asian J. 2012, 7, 2854-2863.

25 APEX 2 \& SAINT. Software for CCD Diffractometers. Madison, USA: Bruker AXS Inc; 2012.

26 Sheldrick, G. M. Acta Crystallogr. 2015, C71, 3-8. 